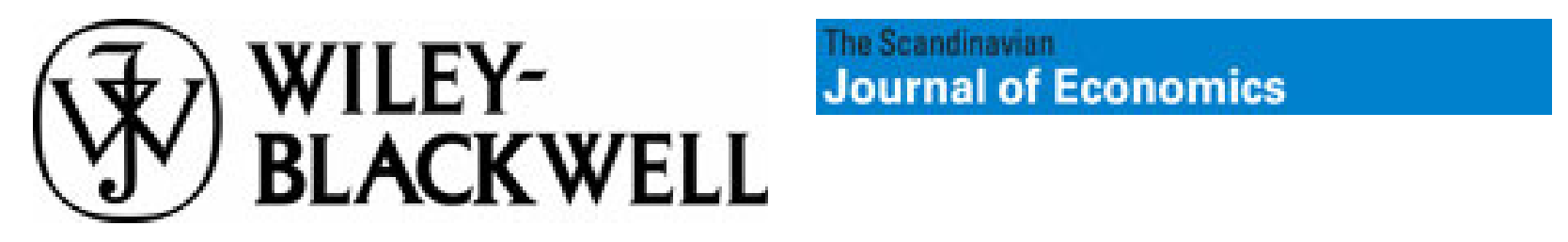

Hedonic Prices, Property Values and Measuring Environmental Benefits: A Survey of the Issues

Author(s): A. Myrick Freeman, III

Source: The Scandinavian Journal of Economics, Vol. 81, No. 2, Measurement in Public Choice (1979), pp. 154-173

Published by: Blackwell Publishing on behalf of The Scandinavian Journal of Economics

Stable URL: http://www.jstor.org/stable/3439957

Accessed: $13 \overline{/ 09 / 2011 ~ 13: 56}$

Your use of the JSTOR archive indicates your acceptance of the Terms \& Conditions of Use, available at http://www.jstor.org/page/info/about/policies/terms.jsp

JSTOR is a not-for-profit service that helps scholars, researchers, and students discover, use, and build upon a wide range of content in a trusted digital archive. We use information technology and tools to increase productivity and facilitate new forms of scholarship. For more information about JSTOR, please contact support@ jstor.org. 


\title{
HEDONIC PRICES, PROPERTY VALUES AND MEASURING ENVIRONMENTAL BENEFITS: A SURVEY OF THE ISSUES
}

\section{A. Myrick Freeman $I I I^{*}$}

Bowdoin College, Brunswick, Maine, USA and Resources for the Future, Washington, D.C., USA

\begin{abstract}
This paper provides a review of the theoretical basis and the assumptions required in order to use hedonic price equations derived from property value data to obtain measures of the prices and the inverse demand functions for environmental amenities such as air quality. It also includes a review and assessment of existing empirical applications of the technique to problems of air and water quality and urban noise.
\end{abstract}

\section{Introduction}

Since Ridker \& Henning's (1967) pioneering study, there has been growing interest in using property value data as a source of information on the benefits to be expected from controlling environmental disamenities such as air pollution, water pollution, and noise. Along with this interest there has been continuing controversy and debate over the proper theoretical framework for the analysis of property values and the interpretation of regression coefficients. ${ }^{1}$ Although other consistent theoretical models are possible, ${ }^{2}$ most attention has focused on the theory of hedonic prices. Rosen (1974) presented a general theoretical framework for using hedonic prices to analyze the demand for and supply of attributes for differentiated products. And Freeman (1974) showed how this framework could be used to interpret existing studies of the property value-air pollution relationship. More recently, at least two major empirical efforts, Harrison \& Rubinfeld (1978 a) and Nelson (1978b) have been based explicitly on the hedonic price framework.

At the same time that the hedonic technique has been proposed and utilized by some, it has been criticized by others on various grounds. ${ }^{3}$ The criticisms

\footnotetext{
* I am indebted to V. Kerry Smith for helpful comments. All responsibility for errors is my own.

1 See, for example, Freeman (1971) and Anderson \& Crocker (1972).

2 See Polinsky \& Shavell (1976), Polinsky \& Rubinfeld (1977), and Lind (1973).

See, for example, Lave (1972) and (1978), Smith (1976), Mäler (1977), Harris (1978), and Pearce (forthcoming).
} 
include skepticism that observed associations between air pollution and property values reflect a true relationship rather than spurious correlation, claims that the assumptions such as equilibrium in the housing market are so unrealistic as to render the empirical technique invalid, and attacks on the underlying theory as requiring unnecessarily restrictive assumptions about such things as the nature of utility functions.

In this paper I attempt to assess the validity of some of these criticisms. It must be acknowledged at the outset that the hedonic technique is not capable of capturing benefits that people experience away from their place of residence, for example, air quality at the work place, water quality at recreational sites, and so forth. Also, if other techniques are used to estimate other "categories" of benefits such as health or household soiling, they cannot simply be added to property value benefits since they may involve double counting. But these comments are not directed at the logic and validity of the hedonic price technique, per se, but rather at the way in which property value benefit information is combined with other information in assessing the total benefits of pollution control.

In sections that follow I will first briefly review the hedonic technique. The technique involves two separate and conceptually distinct steps: using the hedonic price equation to estimate marginal implicit prices of characteristics, and using these implicit prices to estimate inverse demand functions or marginal willingness to pay functions for groups of households. Subsequent sections will consider each of these steps in more detail, paying particular attention to the assumptions and type of data necessary to implement the technique. Then, since one of the issues is the validity of the observed relationship between property values and environmental amenities, I will review the results of existing studies. Of particular interest will be the consistency of empirical results and the degree to which other variables possibly affecting property values have been controlled for.

To preview my conclusions, one's assessment of the hedonic technique seems to depend upon which end of the telescope one looks through in examining the theory, the assumptions, and the data. The theory is logical and consistent, but it involves a substantial simplification and abstraction from a complex reality. The assumptions are never completely realized in practice. But this is a dubious test of the validity of an empirical model. It is the nature of models in economics that their assumptions are to some extent unrealistic. The data are inadequate; variables are measured with error; and the definitions of empirical variables seldom correspond precisely to the theoretical constructs. But all of these criticisms can be raised against virtually any empirical work in economics. The hedonic technique for estimating benefits seems to pass the appropriate tests about as well, or as poorly, as any empirical technique for estimating such things as demand functions, production functions, consumption functions, and so forth. 


\section{The Theory and Overview}

Estimating the demand for a characteristic of a housing unit, for example its air quality, involves a two step procedure in which first the implicit price of the characteristic is estimated by the application of the hedonic price technique, and then the implicit price is regressed against observed quantities and other variables such as income to estimate the demand function itself. Houses constitute a product class differentiated by characteristics such as number of rooms and size of lot. The price of a house can be taken to be a function of its structural, neighborhood, and environmental characteristics. More formally, let $H$ represent the product or commodity class-housing. Any unit of $H$, say $h_{i}$, can be completely described by a vector of its characteristics, including locational, neighborhood and environmental characteristics. If $S_{j}, N_{k}$ and $Q_{m}$ indicate the vectors of site, neighborhood, and environmental variables respectively, then the price of $h_{i}$ is a function of the levels of those characteristics:

$P_{h i}=P_{h}\left(S_{i 1}, \ldots, S_{i j}, N_{i 1}, \ldots, N_{i k}, Q_{i 1}, \ldots, Q_{i m}\right)$.

The function $P_{h}$ is the hedonic or implicit price function for $H$. If $P_{h}$ can be estimated from the observations of the prices and characteristics of different models, the price of any possible model can be calculated from knowledge of its characteristics.

The marginal implicit price of a characteristic can be found by differentiating the implicit price function with respect to that characteristic. For an environmental characteristic:

$\partial P_{h} / \partial Q_{m}=P_{Q_{m}}\left(Q_{m}\right)$

gives the increase in expenditure on $H$ that is required to obtain a house with one more unit of $Q_{m}$, ceteris paribus.

If (1) is linear in the characteristics, then the implicit prices are constants for households. But if ( 1$)$ is nonlinear, then the implicit price of an additional unit of a characteristic depends on the quantity of the characteristic being purchased and, depending on the functional form of (1), perhaps on the quantities of other characteristics as well. Equation (1) need not be linear. Linearity will occur only if consumers can "arbitrage" attributes by untying and repackaging bundles of attributes (Rosen, 1974, pp. 37-38).

Assume that equation (1) has been estimated for housing in an urban area. If the household is assumed to be a price taker in the housing market, it can be viewed as facing an array of implicit marginal price schedules for various characteristics. A household maximizes its utility by simultaneously moving along each marginal price schedule until it reaches a point where its marginal willingness to pay for an additional unit of each characteristic just equals the marginal implicit price of that characteristic. If a household is in equilibrium, the marginal implicit prices associated with the housing bundle actually chosen 

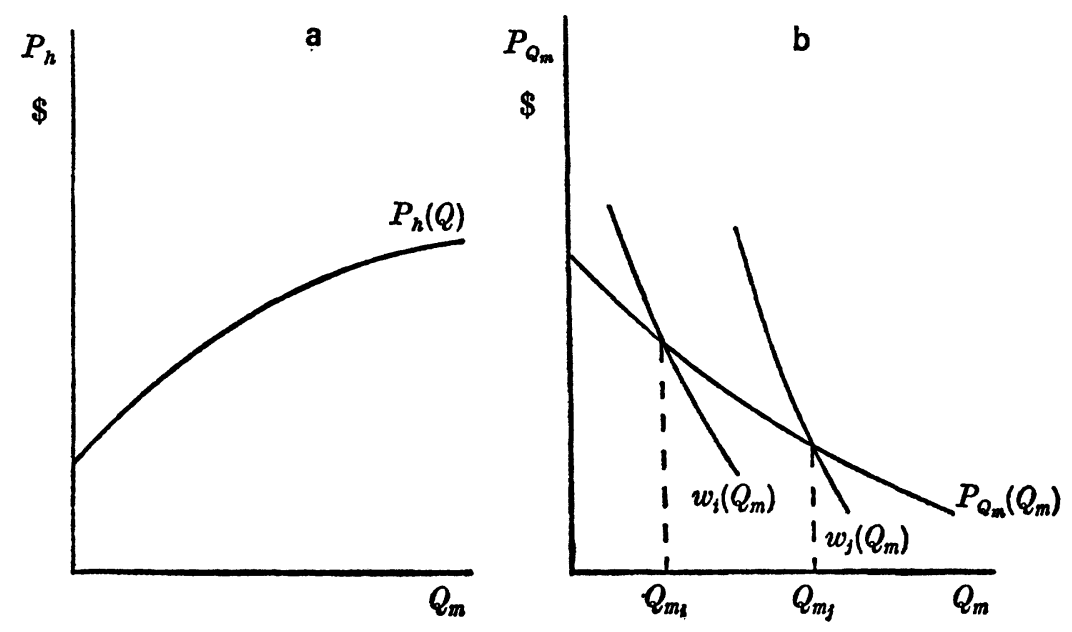

Fig. 1

must be equal to the corresponding marginal willingnesses to pay for those characteristics.

Now let us consider only the implicit price of $Q_{m}$. Fig. $1 a$ shows the partial relationship between $P_{h}$ and $Q_{m}$ as estimated from (1), that is, holding all other characteristics constant. Fig. $1 b$ shows the marginal implicit price of $Q_{m}$, $P_{Q_{m}}\left(Q_{m}\right)$. It also shows the inverse demand or marginal willingness to pay curves for two households $w_{i}\left(Q_{m}\right)$ and $w_{j}\left(Q_{m}\right)$ and the equilibrium positions for these two households. Each household chooses a location where its marginal willingness to pay for $Q_{m}$, is equated with the marginal implicit price of $Q_{m}$. Thus the implicit price function is a locus of household equilibrium marginal willingnesses to pay.

The first stage just described develops a measure of the price of $Q_{m}$ but does not directly reveal or identify the inverse demand function for $Q_{m}$. The second stage of the hedonic technique is to combine the quantity and implicit price information in an effort to identify this inverse demand function. It is hypothesized that the household's demand price or willingness to pay for $Q_{m}$ is a function of its level, income, and other household variables which influence tastes and preferences. In other words:

$w_{i}=w\left(Q_{m i}, M_{i}, \ldots\right)$

Each household's observed $P_{Q_{m}}\left(Q_{m_{i}}\right)$ is taken to be a measure of $w_{i}$. Can this demand function be identified with the information at hand?

There are two special cases. First, if the hedonic price function is linear in $Q_{m}$, identification of the inverse demand function is not possible. This is because the marginal implicit price is constant. The second special case arises when all households have identical incomes and utility functions. In this case, 
equation (2) is itself the inverse demand function. Recall that the marginal implicit price curve is a locus of points on households' marginal willingness to pay curves. With identical incomes and utility functions, these points all fall on the same marginal willingness to pay curve.

If neither special case applies then the supply side of the implicit market for the characteristic must be examined. There are three possibilities. First, if the supply of houses with given bundles of characteristics is perfectly elastic at the observed prices, then the implicit price function of a characteristic can be taken as exogenous to households. A regression of observed levels of the characteristic against the observed implicit prices as defined by (2), incomes, and other socio-economic characteristics of households should identify the demand function. Second, if the available quantity of each model is fixed, households can be viewed as bidding for fixed quantities of models with desired bundles of characteristics. A regression of each household's marginal willingness to pay as measured by its implicit price against the quantity of the characteristic actually taken, incomes and other variables should identify an inverse demand function. Finally, if both the quantities demanded and quantities supplied of characteristics are functions of prices, a simultaneous equation approach can be used. ${ }^{1}$

A major reason for estimating hedonic prices and inverse demand functions is to be able to measure the benefits of changes in the level of environmental amenities. Briefly, a household's marginal benefit for a small improvement in amenities is its marginal willingness to pay-as estimated by the marginal implicit price it faces. For a non-marginal change the benefit is approximated by the area under the inverse demand curve for the change in question. ${ }^{2}$ And aggregate benefits for an urban area are found by summing the relevant household measures across all households.

\section{Measuring Marginal Implicit Prices and Willingness to Pay}

In this section I examine several issues relating to the use of the hedonic price equation as a basis for measuring the marginal implicit prices actually paid by households for housing characteristics such as environmental quality.

Perceptions. One criticism which is sometimes leveled against the application of the property value approach to air pollution is that households really do not perceive differences in air quality or the effects of air pollution. This criticism is not directed at the underlying theoretical model, and it would not seem to be applicable to the use of the model for other types of amenities such as noise. But even in the case of air pollution, this is basically an empirical question. It is hypothesized that air pollution enters utility functions nega-

\footnotetext{
1 For further discussion of this case, see Rosen (1974), pp. 48-51.

2 This assumes income effects are small. This and other aspects of benefit measurement are discussed in more detail in Freeman (1979).
} 
tively; and the model of household behavior predicts that utility differences will be reflected in price differences among housing units. The hypothesis can be rejected if the usual statistical procedures do not find an association between air pollution and property values. To be sure, observed associations do not prove causation. They may be due to chance or due to correlation between a third variable not included in the regressions and property values. But when such associations are found in repeated statistical experiments with different data sets and different cities, they tend to support the hypothesis. We will review the empirical evidence concerning the possible association in a later section.

Equilibrium. Interpreting the marginal implicit prices as measures of households' marginal willingnesses to pay requires the assumption that each household is in equilibrium with respect to a given vector of housing prices and that the vector of housing prices is the one that just clears the market for a given stock of housing and attributes including environmental amenities. In other words it is the price vector which makes all participants in the market in aggregate just willing to hold the existing stock of housing. For these two aspects of equilibrium to be fully achieved, we require first that households have full information on all housing prices and attributes and that their transactions and moving costs be zero, and second that the price vector adjust instantaneously to changes in either demand or supply. The market for housing can be viewed as a stock-flow model where the flow (change in stock) is a function of prices, but the prices at any point in time are determined only by the stock at that point in time.

Now this idealized model is clearly not an accurate representation of real world housing markets. But in evaluating the strength of this criticism of the hedonic price model, one must focus on several distinct issues. The first concerns the accuracy of the price data itself. Where the data are based on assessments, appraisals, or self-reporting, they may not correspond to actual market prices. The errors in measuring the dependent variable will tend to obscure any underlying relationship between true property value measures and environmental amenities. But estimates of the relationship will not be biased unless the errors themselves are correlated with other variables in the model. The best evidence on this question comes from comparisons of owners' self-reported values and expert appraisals. In general, the errors appear to be small on the average and random. ${ }^{1}$ Also, some studies have been able to use actual sales data. Results are broadly consistent between those based on selfreported values and those based on actual transactions.

1 Kain \& Quigley (1972) report no significant correlations between the errors and various descriptive characteristics of the housing bundles being valued. See also Nelson (1978a). Although the comparison is with expert appraisals, not market transactions, appraisors use analyses of the sale prices of comparable properties as a major basis for establishing appraised values. Hence, appraisals should be closely correlated with market values with only a small and random error component. 
A second set of issues concerns the speed of adjustment of the market to changing conditions of supply and demand. If adjustment is not complete, observed marginal implicit prices will not accurately measure household marginal willingnesses to pay. The major question is whether imperfect adjustment will lead to systematic biases in estimates of willingness to pay.

Consider first households' imperfect adjustment to changing prices. Even though housing prices change, households will not move unless the potential utility gain to returning to full equilibrium exceeds the information costs, transactions costs, and moving costs associated with the change. These costs help to define a band within which observed marginal implicit prices can diverge from household marginal willingnesses to pay for housing attributes. An increase in housing prices need not affect the marginal implicit prices of attributes. But if housing prices change so that the marginal implicit price schedule for an attribute moves consistently in one direction, households will consistently lag in their adjustment to that change. And the marginal willingnesses to pay will be overstated or understated according to whether the marginal implicit price is rising or falling. I am not aware of any analyses of time trends of marginal implicit prices that could shed light on the empirical importance of this source of bias.

This discussion has presumed that the changes in marginal implicit prices were exogenous to households. But these changes will only occur in response to changes in households' demands or changes in the supplies of attributes. A similar line of reasoning applies here. If either supply or demand is changing continuously in one direction, this can bias estimates of marginal willingness to pay. For example, if the demand for an attribute is increasing, marginal implicit prices will underestimate true marginal willingnesses to pay. This is because marginal willingnesses to pay will not be translated into market transactions which affect marginal implicit prices until the potential utility gains pass the threshold of transactions and moving costs.

A third issue concerns expectations about future environmental amenity levels. Market prices for long-lived assets such as housing reflect the discounted present value of the stream of expected future services from that asset. A change in expectations about future environmental amenity levels can affect housing prices and marginal implicit prices independently of the present level of these amenities. For example, if there are widespread expectations of an improvement in air quality, and the market adjusts reasonably quickly to these expectations, the price differential between presently dirty and clean houses should decrease. Correlating these prices with existing levels of air pollution would lead to an underestimate of the marginal implicit price of air quality. ${ }^{1}$

To summarize, divergences from full equilibrium of the housing market in

1 See, for example, Mäler (1977), p. 360.

Scand. J. of Economics 1979 
many circumstances will only introduce random errors into the estimates of marginal willingnesses to pay. However, where market forces are moving continuously in one direction, or are expected to move in one direction, incomplete market adjustment and/or full adjustment to changing expectations can introduce biases in both directions. One should be much more cautious about utilizing the hedonic price approach in those cities and at points in time during which market forces and environmental quality levels are changing rapidly. (Granted that "rapidly" is an imprecise term.) However, it is also possible in these circumstances to determine the direction of bias. Thus, estimates of marginal willingness to pay or benefits derived from such studies can be labeled as upper bound or lower bound on the basis of that analysis.

Limited Range of Alternative Models. In order to interpret observed marginal implicit prices as equilibrium marginal willingnesses to pay, it is necessary to assume that there is a sufficiently wide variety of housing models available such that every household is in equilibrium. The implicit price function defines an opportunity locus across attribute space. A household chooses a housing model such that its indifference surface is tangent to the given opportunity locus, provided that a model with that precise set of attributes is available. If not, the household must pick the nearby housing model which gives the highest utility level. But then the first order conditions for utility maximization are not satisfied as equalities. ${ }^{1}$

The model is based on an assumption that the implicit price function is smooth or differentiable, and continuous. But this is an artifact of the statistical and mathematical technique. There are two sorts of problems. First, the statistically fitted implicit price function is a better approximation the larger the number of units and the more continuous the variation in characteristics among units. A small number of distinctly different types of housing units might be better represented by an opportunity surface consisting of a series of linear segments, but where households could only locate at the corners. The fewer the number of types of units, the greater is the error introduced by treating computed marginal implicit prices as representing equilibrium marginal willingnesses to pay. However, this in itself should not introduce bias into the estimates derived from the technique. And in any event, for large urban housing markets there seems to be wide variation in the types of units available. The smooth continuous implicit price function should be a reasonable approximation of reality.

The second type of problem arises if there are no units available with particular combinations of attributes. If there are substantial gaps in the opportunity locus, some households will not be able to satisfy the first order conditions as equalities. This could be a problem for certain subsets of the urban population. Harrison \& Rubinfeld $(1978 b)$ have uncovered an anomaly which

1 Mäler (1977) discusses this set of issues on pp. 361-362.

Scand. J. of Economics 1979 


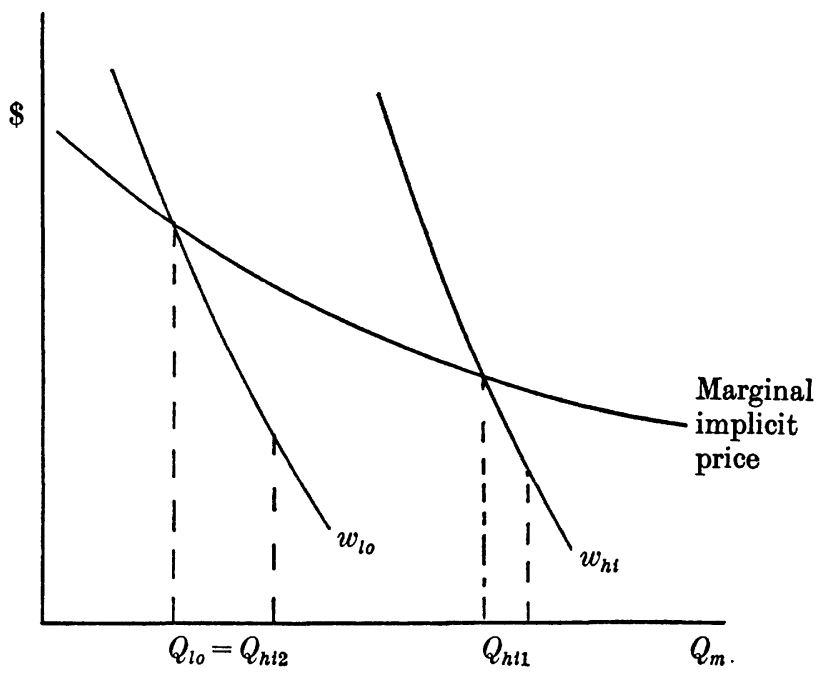

Fig. 2

might be explained by this phenomenon. They estimated both an implicit price function for housing in the Boston SMSA and marginal willingness to pay as a function of nitrogen oxides levels and incomes. Fig. 2 shows the marginal implicit price function for nitrogen oxides $\left(Q_{m}\right)$ and the estimated marginal willingness to pay functions for high income and low income households. In examining the distributional implications of a change in nitrogen oxides levels, Harrison \& Rubinfeld found that some high income households experienced a large benefit due to their initial location in a high nitrogen oxide area. This is contrary to the implications of the simple model for two reasons. First, high income households should locate in low pollution areas and thus have low willingnesses to pay at the margin for air quality improvements. Also, the postulated policy generated lower improvements in air quality in those areas with higher initial air quality levels.

One possible explanation for the anomaly is that some high income households wish to consume bundles of housing with low nitrogen oxides and high levels of some other attribute, say the cultural amenities of the urban environment, but that there are no housing units available which supply these two attributes jointly in the appropriate combination. If that is the case, the marginal implicit price function would not exist to the right of $Q^{*}$ in Fig. 3. The high income household would settle at $Q^{*}$ because that is the best it can do. But the observed marginal implicit price $\left(P_{q}\right)$ can no longer be taken as representing the equilibrium marginal willingness to pay for the high income household.

How important is this problem in practice? As the example indicates, one cannot rule it out on a priori grounds. In fact, the problem is almost certain to exist for some sub-groups in some urban areas. But one need not conclude 


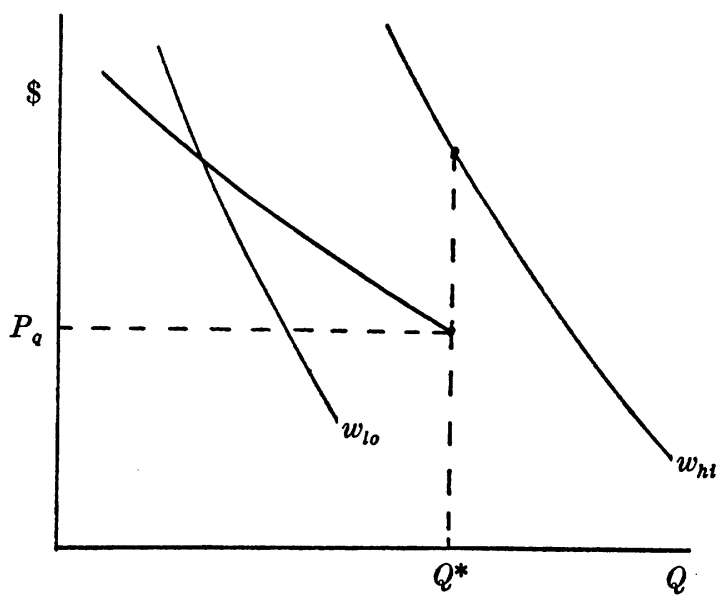

Fig. 3

that aggregate estimates are so unreliable as to be of no use because the aggregate model does not perfectly replicate the situation of every component of the aggregate. This is a problem to which empirical researchers must be sensitive. Examination of the disaggregated behavior of the model such as that carried out by Harrison \& Rubinfeld could be helpful in identifying the existence of such problems and judging their seriousness.

Market Segmentation. Mahlon Straszheim (1974) was the first to raise the question of market segmentation in the context of estimating hedonic price functions for housing. He argued that the urban housing market really consisted of a series of separate, compartmentalized markets with different hedonic price functions in each. As evidence in support of the segmentation hypothesis, Straszheim showed that estimating separate hedonic price functions for different geographic areas around San Francisco Bay reduced the sum of squared errors for the sample as a whole.

For different hedonic price functions to exist in an urban area two conditions must be met. First, purchasers in one market stratum must not participate significantly in other market strata. In other words, there must be some barrier to mobility of buyers among market strata. These barriers could be due to geography, discrimination, lack of information, or a desire for ethnically homogeneous neighborhoods. The second condition is that either the structure of demand, the structure of supply, or both must be different across regions. Either buyers in separate sub-markets must have different structures of demands, or the structure of characteristics of the housing stocks must be different. Even with buyer immobility, if demand and supply structures are the same, they will produce similar structures of hedonic prices. And perfect mobility and information on the part of buyers will eliminate differences in the implicit prices for any characteristic across market strata. 
If market segmentation does exist, the hedonic price function estimated for the urban area as a whole will provide faulty estimates of the implicit prices facing subsets of buyers in different market segments. If market segmentation does exist, separate hedonic price functions must be estimated for each segment.

It is not clear how significant the problem of market segmentation is at the empirical level for air pollution-property value studies. Only two studies have tested their data for market segmentation. Harrison \& Rubinfeld (1978 $a$ ) stratified their Boston data on the basis of income, accessability to employment, and household social status. They did not report the effect of stratification on the implicit price function. But they did report that estimates of benefits calculated from the implicit price function were reduced by up to $41 \%$ depending upon the basis for market stratification. Thus there apparently was a significant effect on the implicit price function. On the other hand, Nelson $(1978 a)$ stratified his Washington, D.C. sample according to urban vs. suburban Census tracts. A Chow (F) test could not reject the hypothesis that the hedonic price functions were the same in the two submarkets. In a study which did not include air pollution, Schnare \& Struyk (1976) stratified their sample of individual sales transactions from the Boston SMSA on the basis of: median income of the Census tract in which the housing unit was located; number of rooms in the housing unit; a measure of the accessability of the housing unit; and by political jurisdiction. Their tests indicated different hedonic price functions for sub-markets stratified by these characteristics.

It should be noted that the existence of market segmentation does not render the hedonic price technique invalid. Rather, it makes its application more difficult. If the appropriate basis for segmentation can be identified, it is conceptually possible to estimate separate implicit price functions for each sub-market. Although these functions would be different across markets, they each would accurately reflect the outcome of the market process in each sub-market. Thus, they could be used to estimate equilibrium marginal willingnesses to pay.

The Utility Function. Does the estimation of hedonic price equations impose any restrictions on the structure or arguments of households' utility functions? Recall that the implicit price function is a reduced form equation reflecting the interaction of supply and demand in a housing market. It is based on the hypothesis that the price of a unit of housing is a function only of its characteristics. Buyer characteristics should not enter the equation since the characteristics of potential buyers are the same for all housing units. ${ }^{1}$

There are two aspects of households' utility functions which do have a role in the specification of the implicit price function. First, the only housing characteristics which can affect housing prices are those which matter to

\footnotetext{
1 If there is market segmentation, buyer characteristics may be one basis for stratifying the market. But within sub-markets, buyer characteristics are the same.
} 
households. So the housing characteristics used to explain housing prices should be the same as those which are arguments in households' utility functions. If a characteristic matters but is omitted from the hedonic price equation, the coefficients of other characteristics could be biased.

Second, the way in which a particular characteristic enters a utility function can, in conjunction with the structure of supply of characteristics, affect the shape of the hedonic price function. For example, unless the utility function is strongly separable in a particular characteristic, a household's marginal willingness to pay for that characteristic will depend upon the levels of other characteristics as well. This means that the functional form of the implicit price function should allow for the possibility that the marginal implicit price of a particular characteristic might not be independent of the levels of other characteristics as well. The functional form should also allow for the possibility that the marginal implicit price function of a characteristic may be either upward sloping or downward sloping. The slope of the marginal implicit price function cannot be deduced from examining the utility function. Rather it depends on the interaction of demand and supply forces.

\section{Inverse Demand Functions}

Estimation of inverse demand functions for housing attributes such as environmental quality involves a second stage of analysis in which observations of households' quantities actually taken are combined with estimates of implicit prices generated from the hedonic price function. For each household in a housing market we have one observation of a price and quantity combination. The question is whether the cross-section data for all households operating in the same market can be used to estimate household demand or inverse demand functions. In this section, I deal with two issues: the identification problem, and the necessary restrictions on utility functions.

The Identification Problem. The steps necessary to identify properly the demand function for a characteristic depend on what assumptions are made about the supply side of the implicit market. One approach is to assume that the supply of air quality is perfectly inelastic with respect to price or willingness to pay at each residential location; see Harrison \& Rubinfeld (1978a). In other words, at a given location, air quality is independent of households' willingness to pay. Thus a fully identified inverse demand curve could be estimated by regressing equilibrium marginal prices on quantities, incomes, and other variables.

Nelson (1978b) took a different approach based on a model of the supply of land to residential uses. With the total urban land area fixed, the supply for residential uses is inversely related to the demand for urban land for alternative uses. If the price for residential land increases, land will be shifted away from 
other uses toward housing. The difficulty with this approach is that there is no economic or behavioral mechanism linking the supply of land to the air quality over that land or the willingness to pay for air quality. An increase in the willingness to pay for air quality does not necessarily mean an increase in the demand for land; and if the demand for residential land increases, it could be met with land of either high or low air quality. 1

The supply mechanism affecting the implicit price of air quality is the number of houses with a given air quality. For example, the larger the number of clean air houses, the lower their price relative to other types of houses, ceteris paribus, and the lower the marginal implicit price of clean air derived from the hedonic price equation. The number of houses of high air quality can be increased either by an improvement in air quality over the urban area, or by increasing the number of houses available in the clean air region. With present institutional arrangements, the former can be assumed to be unresponsive to price; but the latter may be somewhat price elastic.

The question of which assumption, exogenous or endogenous supply, is more appropriate boils down to the speed of the supply side adjustment to price changes relative to the speed at which housing prices adjust to changes in supply. In order to use the hedonic price approach at all, it is necessary to assume that the observed housing prices approximate equilibrium prices. The assumption of rapid price adjustment is basic to the technique. On the other hand, since supply adjustments typically require changes in land use patterns including replacing old structures and adding to overhead capital, they are likely to proceed slowly - at speeds measured in years. This is an argument for treating the supply side as exogenous. But it is recognized that the question is an empirical one. And there may be instances, for example in rapidly growing regions, where the short run assumption would be inappropriate.

The Utility Function. One question is whether it is necessary to assume identical utility functions or underlying structures of preferences for all households. The answer is yes. ${ }^{2}$ Whenever observations of households' prices and quantities are pooled to estimate demand functions, it is necessary to assume that all households in the pool have structures of demand which are the same except for those variables which are controlled for in the regression equation. The control variables normally include income, but also could be extended to include other socio-economic characteristics postulated to affect demand. Examples might include age, family size, or education.

Some form of this assumption is necessary for all empirical demand estimation. The question is not whether the assumption is reasonable, but whether

\footnotetext{
1 Nelson specified the offer price of land as a function of its quantity. But in the context of his model, quantity of residential land should $b \theta$ a function of price and the determinants of non-residential land use.

2 For a strong defense of the proposition that tastes are not only stable over time but similar among people, see Stigler \& Becker (1977).
} 
all of the appropriate "taste" variables affecting demand have been included in the model specification. In the case of air pollution, there have been only two studies utilizing the hedonic price technique which have gone beyond the stage of measuring marginal implicit prices and have attempted to estimate inverse demand functions; see Nelson (1978b) and Harrison \& Rubinfeld (1978 $a$ ). In both cases, their inverse demand functions included no taste variables other than income. The lack of other control variables might be an alternative explanation for the anomoly in the Harrison \& Rubinfeld results mentioned earlier. Some high income individuals without children might have a different marginal rate of substitution between urban amenities and air quality than other individuals with similar incomes but different family situations. If the estimated demand function had included variables to reflect differences in demographic characteristics, this anomoly might not have appeared.

A second question concerns possible restrictions on the assumed form of the underlying utility function. Some form of restriction may be useful in simplifying the demand or inverse demand functions to be estimated. Separability is perhaps the most helpful form of restriction in that it makes the demand for a good a function only of the prices of those goods in the same utility branch. Other prices and quantities can be omitted from the demand function being estimated without biasing the price coefficients. The simplest case is if the utility function is separable in the environmental amenity. Then the inverse demand function makes marginal willingness to pay a function only of the amenity, income and other taste parameters. This is the implicit assumption underlying the studies by Harrison \& Rubinfeld (1978a) and Nelson (1978b). Harrison \& Rubinfeld reported that they did investigate the results of including levels of other housing attributes in their marginal willingness to pay functions. They said that in general these variables had little effect on estimates of total willingness to pay for non-marginal changes in air quality. However, some of these additional variables were significant in their willingness to pay equations. ${ }^{1}$

If the utility function is not in fact separable, then the omission of other price or quantity variables will bias the estimate of the effect of the environmental amenity on marginal willingness to pay. A less restrictive assumption would be that the utility function is separable in the attributes of housing including the amenity. Even this form of separability may be too restrictive in principle. There could be non-housing goods or services which are either complements to or substitutes for various attributes of housing, including environmental quality. However, even where no separability conditions can be reasonably invoked, one can still reasonably argue that many cross-price effects are close enough to zero to ignored. Also, individuals in a single urban area constituting a unified market face identical prices for most undifferentiated

${ }^{1}$ See Harrison \& Rubinfeld (1978a), p. 90.

Scand. J. of Economics 1979 
goods and services. Therefore, the prices of those goods which are the same across all individuals can be omitted from the demand function specification. Finally, there may be cases where one would expect the marginal willingness to pay for an amenity to depend upon the quantity of some non-housing good or service consumed. An example might be the ownership of musical instruments and the marginal willingness to pay to avoid noise. Then variables reflecting these consumption patterns should be included in the marginal willingness to pay function. But the justification is that they are proxies for differences in the underlying preference structure.

In summary, whether some form of separability assumption should be invoked seems not to be an important question in itself. What is important is the list of variables to be included in the model specification. And here, judgment and experience with the data will probably turn out to be the best guide.

\section{Empirical Studies of Amenities and Property Values}

The purpose of this section is to review those studies of housing prices which have been based on the hedonic price technique and which have included some type of environmental amenity as an explanatory variable. I am aware of fifteen different studies which have included some measure of air quality. These cover eleven different cities in the U.S. and Canada. Other studies have used measures of noise, water quality, and proximity to shoreline.

Most of the air pollution studies have used data from the U.S. Census of Housing and Population, both for property value and rental measures and for explanatory variables. For each Census tract the Census reports the median of owner estimates of the property for owner occupied housing. As an alternative to the aggregate Census data, Crocker (1970), B. Smith (1978) and Sonstelie \& Portney (1977) were able to use data on transactions in individual properties in their studies of Chicago and San Mateo County. The Census also reports rents paid for renter occupied housing. Goodwin (1976) studied the rental market only. Anderson-Crocker (1971) and Spore (1972) estimated separate relationships for both property values and rentals. In these two studies the effect of air pollution on rentals does not appear to be as strong as on property values.

As for air pollution measures, the earlier studies focused primarily on the major stationary source air pollutants, i.e., sulfur dioxide and suspended particulates. One problem with the air pollution data is that they are often not contemporary with data on property values and other explanatory variables. For example, all four of the St. Louis studies used 1963 pollution variables to explain 1960 property values. The most extreme case is Peckham's study of Philadelphia (1970) which uses 1969 pollution data to explain 1960 property 
values. Those studies using property values from the 1970 Census have been able to use essentially contemporary air pollution data.

Four studies, Nelson (1978b), Harrison-MacDonald (1974), Harrison-Rubinfeld (1978a), and Sonstelie \& Portney (1977), have focused attention on mobilesource pollutants, i.e., oxidants and nitrogen oxides. The Harrison-MacDonald and Harrison-Rubinfeld studies were innovative in their reliance on air pollution values calculated from a dispersion model rather than from actual readings. The question here is whether the state-of-the-art in dispersion modeling is adequate to support this use of the output of such models.

Of major interest is the extent to which these studies have controlled for other variables hypothesized to effect property values, that is, have they reduced the likelihood that the observed correlation between air pollution and property values is spurious. It is not practical in the space allowed to present a detailed review of the data and model specification for each of these studies. The studies have used explanatory variables which fall into two groups: characteristics of the property, including location, lot size and structural characteristics; and characteristics of the neighborhood. The latter category includes socio-economic characteristics of the neighborhood population, and public services such as schools, police, and accessibility to parks. Some studies controlled for as few as two and as high as ten property characteristics and as few as two and as high as twenty-three neighborhood characteristics. Two studies controlled only for neighborhood, omitting any property characteristic variables.

It is important to control for accessibility to the central business district (CBD) and the value of reduced travel time by including some accessability variable in the property value equation. The effects of accessability could be confounded with the effects of air pollution (which is often worse closer to the $\mathrm{CBD}$ ). All but one of the studies used distance to CBD or some other locational measures to control for accessability. The exception is the HarrisonMacDonald (1974) study of Los Angeles where it is difficult to identify a single center to use as a point of reference. Instead Harrison \& MacDonald used a variable which reflected accessability to major freeways.

Overall, the selection of explanatory variables seems to be almost haphazard. Convenience and data availability appear to be the major determinants of this part of model specification. Virtually all of the studies reviewed can be criticized on one or another aspect of their model specification. The variety of model specifications raises some questions about the extent to which results are sensitive to the choice of explanatory variables.

One of the purposes of the Harrison-Rubinfeld (1978a) study was to examine the sensitivity of the air pollution-property value relationship (and benefit estimates derived therefrom) to the specification of the hedonic housing price functions. They experimented with various functional forms, and they reestimated the relationship after deleting or adding other pollution measures 
and measures of property and neighborhood characteristics. They concluded that the estimates of the implicit price function for air quality are quite sensitive to the specification of the housing value equation. However, given the implicit price function, estimates of the inverse demand function and benefits are relatively stable across alternative specifications.

It is difficult to summarize the results of the studies reported here, since they cover a number of cities, different time periods, use different data bases, empirical techniques, and model specifications. However, two things stand out. First, the hypothesis that property values within an urban area are affected by air pollution is generally supported by the evidence. Only two studies, Wieand (1973) and Steele (1972) report negative results. They were both based on alternatives to the standard property value dependent variable. Second, the numerical values reported are generally plausible and broadly consistent both within cities as derived from different studies and between cities. However, precise comparisons are not warranted because of differences in the approaches taken.

Nelson's study (1978a) of Washington was unique in that he included two different types of environmental amenities-air quality and reduced noise from traffic. He found that the significant coefficients for both sets of variables were statistically significant and within the range of results from other studies. ${ }^{1}$

The hedonic technique has also been applied to water quality. David (1968) investigated property values surrounding sixty artificial lakes in Wisconsin. Lakes were classified as having poor, moderate, or good water quality by officials at State agencies. Water quality was a significant variable in explaining property values around the sixty lakes.

Brown \& Pollakowski (1977) estimated the values of access to the shoreline and "set back" or open space between the residential area and the shoreline. They regressed prices of properties around lakes in Seattle on distance from shoreline and distance of set back along with other structural and locational characteristics. They assumed identical utility functions and income so that they could interpret the marginal implicit price function as a marginal willingness to pay curve. Coefficients were of the expected sign and statistically significant.

\section{Conclusions}

In this paper I have attempted to examine in some detail a number of criticisms of the hedonic price technique as applied to measuring the demand for environmental amenities in order to determine whether they represent fundamental problems or whether they can be classified as normal discrepancies between

\footnotetext{
1 Nelson also reviewed the results of other hedonic studies of the effect of both aircraft and traffic noise on property values. See Chapter 6.
} 
the theoretical ideal and the practical realities of the sort empirical research always confronts. It must be acknowledged that there are many respects in which the actual data diverge from the theoretical ideal and in which the assumptions about the nature of the housing market and preferences are oversimplifications. But the question is not whether the model is perfect, but rather does it provide a usable vehicle for increasing our knowledge?

The results from over a dozen studies indicate the model has substantial explanatory power with respect to housing prices. The major questions concern the possibility of market segmentation and limits on the range of available models which may force some households into corner solutions. Also the Harrison-Rubinfeld work indicates that hedonic price functions are sensitive to model specification. There is substantially less experience with using marginal implicit prices to estimate inverse demand functions for amenities such as air quality. But here, the empirical problems seem less severe, provided that the first stage analysis yields accurate estimates of marginal implicit prices.

Finally, while I believe that the hedonic price technique does offer promise as a means of estimating demands, few of the studies so far published are fully satisfactory in terms of their use of data, empirical technique and interpretation. There is much to be learned by studying new cities, and reworking existing data sets to take advantage of our greater understanding of the hedonic price technique. These studies should also attempt to investigate more carefully some of the issues identified in this paper (for example, market segmentation and the identification problem) in an effort to determine the extent and seriousness of the problems they pose.

\section{References}

Anderson, Robert J. \& Crocker, Thomas: Air pollution and property values: A reply. Review of Economics and Statistics, November 1972.

Anderson, Robert J. \& Crocker, Thomas: Air pollution and residential property values. Urban Studies, 1971.

Brown, Gardner M.\& Pollakowski, Henry O.: Economic valuation of shoreline. Review of Economics and Statistics, August 1977.

Crocker, Thomas: Urban air pollution dam. age functions. Theory and measurement. Riverside, University of California, 1970 (available through NTIS: PB 197-668).

David, Elizabeth L.: Lake shore property values: A guide to public investment in recreation. Water Resources Research, August 1968.
Freeman, A. Myrick, III: Air pollution and property values: A methodological comment. Review of Economics and Statistics, November 1971.

Freeman, A. Myrick, III: On estimating air pollution control benefits from land value studies. Journal of Environmental Economics and Management, 1974.

Freeman, A. Myrick, III: The benefits of environmental improvement: Theory and practice. Johns Hopkins University Press, 1979.

Goodwin, Susan A.: Measuring the value of housing quality: A note. Journal of Regional Science, April 1977.

Harris, A. H.: Valuing environmental amenity: A critique of the house price approach. University of Aberdeen, Depart- 
ment of Political Economy, Discussion Paper 78-01, 1978.

Harrison, David, Jr \& MacDonald, Robert: Willingness to pay in Boston and Los Angeles for a reduction in automobilerelated pollutants. In National Academy of Sciences, Air quality and automobile emission control, Vol. IV: The cost and benefits of automobile control. Washington, D.C., 1974.

Harrison, David, Jr \& Rubinfeld, Daniel L.: Hedonic housing prices and the demand for clean air. Journal of Environmental Economics and Management, $1978 a$.

Harrison, David, Jr \& Rubinfeld, Daniel L.: The distribution of benefits from improvements in urban air quality. Journal of Environmental Economics and Management, $1978 b$.

Kain, John F. \& Quigley, John M.: Note on owner's estimate of housing value. Journal of the American Statistical Association 67, no. 340, December, pp. 803-06.

Lave, Lester: Air pollution damage: Some difficulties in estimating the value of abatement. In Environmental quality analysis (ed. Allen V. Kneese and Blair T. Bower). Johns Hopkins University Press for Resources for the Future, 1972.

Lave, Lester: Comment. In Approaches to controlling air pollution (ed. Ann Friedlaender). MIT Press, 1978.

Lind, Robert C: Spatial equilibrium, the theory of rents, and the management of benefits from public programs. Quarterly Journal of Economics, May 1973.

Mäler, Karl-Goran: A note on the use of property values in estimating marginal willingness to pay for environmental quality. Journal of Environmental Economics and Management, October 1977.

Nelson, J. P.: Economic analysis of transportation noise abatement, Cambridge, $1978 a$.

Nelson, J. P.: Residential choice, hedonic prices, and the demand for urban air quality. Journal of Urban Economics, $1978 b$.

Peacre, D. W.: The valuation of pollution damage: Noise nuisances. In Readings in environmental economics (ed. J. Butlin). London, forthcoming.
Peckham, Brian: Air pollution and residential property values in Philadelphia. Process, 1970.

Polinsky, A. Mitchell \& Rubinfeld, Daniel L.: Property values and the benefits of environmental improvements: Theory and measurement. In Public economics and the quality of life (ed. Lowdon Wingo and Alan Evans). Johns Hopkins University Press, 1977.

Polinsky, A. Mitchell \& Shavell, Steven: Amenities and property values in a model of an urban area. Journal of Public Eco. nomics, January-February 1976.

Ridker, Ronald \& Henning, John A.: The determinants of residential property values with special reference to air pollution. Review of Economics and Statistics, 1967.

Rosen, Sherwin: Hedonic prices and implicit markets: Product differentiation in pure competition. Journal of Political Economy, January-February 1974.

Schnare, Ann B.: Racial and ethnic price differentials in an urban housing market. Urban Studies, 1976.

Schnare, Ann B. \& Struyk, Raymond J.: Segmentation in urban housing markets. Journal of Urban Economics, April 1976.

Smith, Barton A.: Measuring the value of urban amenities. Journal of Urban Economics, 1978.

Smith, V. Kerry: The economic consequences of air pollution. Ballinger, 1976.

Sonstelie, Jon C. \& Portney, Paul R.: Gross rent and a reinterpretation of the Tiebout hypothesis, 1977.

Spore, Robert: Property value differentials as a measure of the economic costs' of air pollution. Pennsylvania State University, Center for Air Environment Studies, 1972.

Steele, William: The effect of air pollution on the value of single-family owner-occupied residential property in Charleston, South Carolina. Masters Thesis, Clemson University, 1972.

Stigler, G. J. \& Becker, G. S.: De gustibus non est disputandum. American Economic Review, March 1977.

Straszheim, Mahlon: Hedonic estimation of 
housing market prices: A further comment. Review of Economics and Statistics, August 1974.

Wieand, Kenneth F.: Air pollution and property values: A study of the St. Louis area. Journal of Regional Science, April 1973.

Zerbe, Robert, Jr: The economics of air pollution: $A$ cost benefit approach. Ontario Department of Public Health, 1969. 